\title{
Editorial \\ Nutritional and Antioxidant Value of Horticulturae Products
}

\author{
Lucia Guidi 1,2,*(D), Luigi De Bellis ${ }^{3, *(D)}$ and Alberto Pardossi 1,2,*(D) \\ 1 Department of Agriculture, Food and Environment, University of Pisa, I-56124 Pisa, Italy \\ 2 Interdepartmental Research Center Nutrafood "Nutraceuticals and Food for Health", University of Pisa, \\ I-56124 Pisa, Italy \\ 3 Department of Biological and Environmental Sciences and Technologies, University of Salento, \\ I-73100 Lecce, Italy \\ * Correspondence: lucia.guidi@unipi.it (L.G.); luigi.debellis@unisalento.it (L.D.B.); \\ alberto.pardossi@unipi.it (A.P.)
}

check for

updates

Citation: Guidi, L.; De Bellis, L.;

Pardossi, A. Nutritional and

Antioxidant Value of Horticulturae

Products. Horticulturae 2022, 8, 4 .

https://doi.org/10.3390/

horticulturae 8010004

Received: 17 November 2021

Accepted: 24 November 2021

Published: 21 December 2021

Publisher's Note: MDPI stays neutral with regard to jurisdictional claims in published maps and institutional affiliations.

Copyright: (c) 2021 by the authors. Licensee MDPI, Basel, Switzerland. This article is an open access article distributed under the terms and conditions of the Creative Commons Attribution (CC BY) license (https:// creativecommons.org/licenses/by/ $4.0 /)$.
The recent growing interest towards the nutraceutical and antioxidant value of fruit and vegetables has arisen from their content of phytochemicals, which provide desirable health benefits, beyond basic nutrition, to reduce the risk of major chronic diseases [1]. For this reason, it is necessary for the human diet to contain a good proportion of plant antioxidant compounds. Therefore, horticultural science must dedicate more attention to satisfy the expectations of consumers who are demanding more and more high-quality functional foods.

The Special Issue on the "Nutritional and Antioxidant Value of Horticultural Products" has provided readers with novel insights into some 'unusual' types of foods. In fact, the articles published included information about edible flowers, Italian green tea, and stinging nettle, along with potato and sweet potato.

Demasi et al. [2] investigated the sensory profile of 17 edible flowers (Figure 1) at harvest, and their shelf life and bioactive compound dynamics during cold storage, providing the characteristics and requirements of the different flowers. The authors evaluated the aroma of the flower with 10 sensory descriptors (intensity of sweet, sour, bitter, salt, smell, specific flower aroma, and herbaceous aroma; spiciness, chewiness, and astringency), and, both at harvest and during $14 \mathrm{~d}$ of storage at $4{ }^{\circ} \mathrm{C}$, the flower visual quality, polyphenol and anthocyanin content, and antioxidant activity were evaluated. The paper presents a lot of information concerning flowers' sensory profiles, phytochemical characteristics, and shelf life, which are very useful to select suitable species for the edible flower market; for example, a strong aroma was revealed for Allium ursinum, Dianthus carthusianorum, Lavandula angustifolia, and Leucanthemum vulgare, while the flowers with the longest shelf life were Rosa pendulina (14 days) and Rosa canina (10 days).

Instead, at the University of Pisa (Italy) [3], different post-harvest treatments (air drying at $30,50,60$, and $70{ }^{\circ} \mathrm{C}$, and freeze drying) were applied to Agastache aurantiaca (A.Gray) Lint \& Epling flowers to determine the effects on the bioactive metabolites and volatile compounds. The outcome was that freeze-drying was found to be the best solution to prolong the shelf life and keep the antioxidant compounds of $A$. aurantiaca flowers, despite changes in the aromatic component. In fact, pulegone, the main volatile emitted by fresh flowers, decreases after the different drying treatments while other volatile compounds appeared.

Drying was also applied to stinging nettle (Urtica dioica L.) [4], which is a well-known plant in traditional medicine. Because the technique enables a low-cost product to be stored for long time, dehydrated samples, after freeze-drying (FD), oven-drying (OD), and heat pump drying (HPD), and fresh leaves were subjected to water extraction to emulate their use by the final consumers. HPD gave the best results, even doubling the phenol content and antioxidant activity compared to the fresh sample, but with a reduction of around $40 \%$ in the ascorbic acid content and 10 to over a hundred times higher amounts of some specific phenolic compounds. These findings confirm the value of dehydration techniques, which, however, should always be modulated when used on fresh samples. 


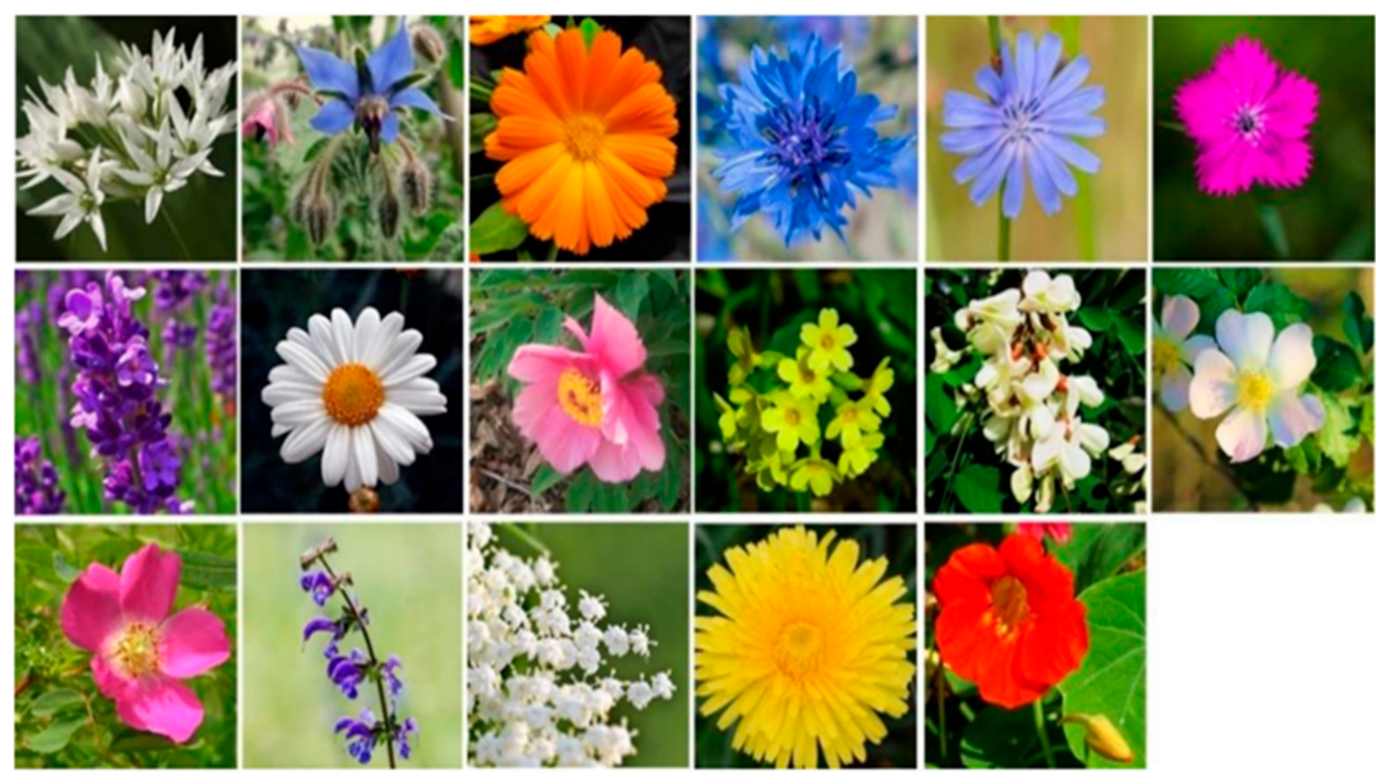

Figure 1. Images of seventeen edible flowers selected by Demasi et al. [2]. From left to right, first line is as follows: Allium ursinum L., Borago officinalis L., Calendula officinalis L., Centaurea cyanus L., Cichorium intybus L., Dianthus carthusianorum L.; second line is as follows: Lavandula angustifolia Mill., Leucanthemum vulgare (Vaill.) Lam., Paeonia officinalis L., Primula veris L., Robinia pseudoacacia L., Rosa canina L.; third line is as follows: Rosa pendulina L., Salvia pratensis L., Sambucus nigra L., Taraxacum officinale Weber, Tropaeolum majus L.

In Italy, in the Lake Maggiore district, the cultivation of Camelia sinensis (L.) O. Kuntze has developed for the production of a quality tea for a niche market. Therefore, the bioactive compounds (polyphenols) and antioxidant activity of the two green teas (the "Camellia d'Oro" tea-TCO, and the "Compagnia del Lago" tea-TCL) were analyzed [5]. The antioxidant activity of the two teas was similar or higher than in other green teas, with TCO characterized by higher antioxidant activity and phenolic content than TCL, indicating that it is possible to grow $C$. sinensis in Italy to a tea of satisfactory quality.

Tilahun et al. [6] realized a study to develop indices to predict the level of total glycoalkaloids (GA) in potato tubers at different greening stages, because the toxicity and beneficial effects of glycoalkaloids depend on the dose and conditions of use. The indices were based on surface color and chlorophyll content for estimation of safe GA levels, which represents basic information that needs to be confirmed and thereafter adapted for use on all potato cultivars.

Finally, Galvao et al. [7] evaluated the quality and nutrient contents of sweet potato, which is considered, by the FAO, as a primary crop for "traditional agriculture", and is also characterized by high variability concerning the color and nutritional value of the edible root. The analyses of 29 sweet potato accessions confirmed that there is considerable variability in nutrient content related to color. Deep-orange-fleshed sweet potatoes contain a higher level of $\beta$-carotene compared to light-orange- and cream-fleshed ones; therefore, $100 \mathrm{~g}$ of edible product can supply $32.3 \%$ of the daily value of vitamin A. The total phenolic content of the purple ecotypes was also higher than the other genotypes. Such high variability in the quality and nutrient contents suggests novel uses of the different color accessions in Europe as well, where sweet potato consumption is not widespread.

Today's food products are all the more appreciated for their content of phyto-nutriceuticals, and, therefore, horticulture has to turn to the supply of products with a variety of valuable metabolites and aromas. It is the task of researchers to study these compounds and enable the enhancement of horticultural products.

Author Contributions: All authors contributed equally. All authors have read and agreed to the published version of the manuscript. 
Funding: This research received no external funding

Institutional Review Board Statement: Not applicable.

Informed Consent Statement: Not applicable.

Conflicts of Interest: The authors declare no conflict of interest.

\section{References}

1. Liu, R.H. Potential synergy of phytochemicals in cancer prevention: Mechanism of action. J. Nutr. 2004, 134, 3479S-3485S. [CrossRef] [PubMed]

2. Demasi, S.; Mellano, M.G.; Falla, N.M.; Caser, M.; Scariot, V. Sensory Profile, Shelf Life, and Dynamics of Bioactive Compounds during Cold Storage of 17 Edible Flowers. Horticulturae 2021, 7, 166. [CrossRef]

3. Marchioni, I.; Dimita, R.; Gioè, G.; Pistelli, L.; Ruffoni, B.; Pistelli, L.; Najar, B. The Effects of Post-Harvest Treatments on the Quality of Agastache aurantiaca Edible Flowers. Horticulturae 2021, 7, 83. [CrossRef]

4. Garcìa, L.M.; Ceccanti, C.; Negro, C.; De Bellis, L.; Incrocci, L.; Pardossi, A.; Guidi, L. Effect of Drying Methods on Phenolic Compounds and Antioxidant Activity of Urtica dioica L. Leaves. Horticulturae 2021, 7, 10. [CrossRef]

5. Falla, N.M.; Demasi, S.; Caser, M.; Scariot, V. Phytochemical Profile and Antioxidant Properties of Italian Green Tea, a New High Quality Niche Product. Horticulturae 2021, 7, 91. [CrossRef]

6. Tilahun, S.; An, H.S.; Solomon, T.; Baek, M.W.; Choi, H.R.; Lee, H.C.; Jeong, C.S. Indices for the Assessment of Glycoalkaloids in Potato Tubers Based on Surface Color and Chlorophyll Content. Horticulturae 2020, 6, 107. [CrossRef]

7. Galvao, A.C.; Nicoletto, C.; Zanin, G.; Vargas, P.F.; Sambo, P. Nutraceutical Content and Daily Value Contribution of Sweet Potato Accessions for the European Market. Horticulturae 2021, 7, 23. [CrossRef] 